\title{
Life history and stable regeneration of the endangered saltmarsh sesarmid crab Clistocoeloma sinense in small populations of the isolated metapopulation of Tokyo Bay, Japan
}

\author{
TAKeshi YuharA ${ }^{1, *} \&$ TOShIO Furota ${ }^{2}$ \\ ${ }^{1}$ Department of Environmental Science, Graduate School of Science, Toho University, Funabashi, Chiba 274-8510, Japan \\ ${ }^{2}$ Faculty of Sciences, Tokyo Bay Ecosystem Research Center, Toho University, Funabashi, Chiba 274-8510, Japan
}

Received 2 October 2013; Accepted 17 March 2014

\begin{abstract}
The saltmarsh sesarmid crab, Clistocoeloma sinense, inhabits the muddy substrata in upper intertidal saltmarshes, and is designated as endangered in Japan. Seasonal changes were investigated in population characters, including abundance, time to sexual maturity, reproductive season, and recruitment of juveniles in a regional metapopulation in Tokyo Bay. Crab samples were collected monthly at five small isolated habitats along the coast of the bay from July, 2011, to March, 2013. Ovigerous females were found during summer in a single peak, and a peak of juvenile recruitment occurred in autumn. Size distribution analysis indicates that growth is slower than for other saltmarsh crab species and life span is at least 4 years. Females reach maturity when they enter the second breeding season following recruitment. The slow growth and reclusive behavior of $C$. sinense may be closely related to the characteristics of its habitat which is under buried stones or wood in the uppermost part of intertidal muddy substrata. Recruitment of juveniles and the presence of breeding females were observed at all five study sites located along the Tokyo Bay coastline, suggesting that each population stably regenerates by larval settlement following larval dispersal and growth in the water column in Tokyo Bay. These data suggest that an increase in the number of small muddy flats with intertidal salt marsh vegetation along the coastline may be the most effective measure to conserve the Tokyo Bay regional metapopulation of this crab species.
\end{abstract}

Key words: endangered sesarmid crab, life history, population structure, saltmarsh, Tokyo Bay

\section{Introduction}

The saltmarsh sesarmid crab Clistocoeloma sinense Shen, 1933, is distributed in estuaries along subtropical and temperate east coasts of Asia, including in Japan (Sakai 1976), Korea (Kamita 1941), China (Dai \& Yang 1991), and Taiwan (Hsueh \& Huang 1996). In Japan, it occurs along the Pacific coasts of central and western Honshu, Shikoku, Kyushu, and Okinawa, in the upper layers of muddy substrata in estuarine intertidal marshes.

Many estuarine ecosystems have been severely disrupted by human activities including overexploitation, pollution, and land reclamation (Lotze et al. 2006). More than $40 \%$ of tidal flats in Japan, including estuarine waters and

\footnotetext{
*Corresponding author: Takeshi Yuhara; E-mail, takeshi.yuhara@gmail.com
}

saltmarshes, have been lost, mainly during the latter half of the 20th century (Japanese Association of Benthology 2012). This destruction has resulted in the reduction of local populations of mudflat/saltmarsh-specific benthic species (Sato 2010).

Approximately $90 \%$ of the tidal flat area in Tokyo Bay, including estuarine saltmarshes, has been lost since the end of the 1970s (Furota 2000). Some mudflat/saltmarshspecific benthic species in the bay have become extinct or endangered (Furota 2007), amongst which $C$. sinense is designated as endangered (The Committee of the Red Data Book Chiba 2011; Japanese Association of Benthology 2012). A recent study of tidal flat benthic animals in remnant saltmarshes in Tokyo Bay reported grapsid crabs to be one of the most common members in the macrobenthic community (Yuhara et al. 2013). The $C$. sinense popula- 




Fig. 1. Study sites (O) and occurrence $(\bigcirc)$ of Clistocoeloma sinense along the coast of Tokyo Bay (from Yuhara et al. 2013).

tions in the bay, which represent the most northern and eastern limits of the geographical distribution of this species, are found in a large variety of estuarine conditions along the coastline, including artificial saltmarshes and small channels as well as in natural estuarine habitats (Fig. 1).

Analyses of the genetic structure of $C$. sinense populations from 17 localities in Japan have revealed low genetic variability among regional populations along the coast (Yuhara et al. 2014). However, although Ise-Mikawa Bay is the next regional location of this crab distribution from Tokyo Bay, the genetic difference between their populations of $C$. sinense is clearer than between other regional populations, suggesting that the Tokyo Bay population is geographically isolated on the Japanese coast.

Information on the population characteristics of C. sinense, including population structure, reproduction, and recruitment, is crucial for effective conservation of the bay population. The aim of the present study is to describe the life history and population characteristics of $C$. sinense under different habitat conditions in the Tokyo Bay. The importance of larval connectivity among the small habitats in the bay is also discussed in relation to conservation of the Tokyo Bay regional metapopulation.

\section{Materials and Methods}

Clistocoeloma sinense has been found at 15 sites where the dominant estuarine saltmarsh vegetation is the reed Phragmites australis along the entire coastline of the bay (Fig. 1; Yuhara et al. 2013). Samples of the crab were collected monthly at five sites with the highest crab densities among the 15 sites.
Shinhama Lagoon $\left(35^{\circ} 40^{\prime} \mathrm{N}, \mathrm{E} 139^{\circ} 55^{\prime} \mathrm{E}\right)$ is an artificial wild bird sanctuary located at the innermost part of the bay. Specimens were collected from two habitats in the lagoon: an artificial muddy intertidal slope with cobbles (SHC) and mudflats with reed marsh (SHS). The Tamasaki site (TS; $\left.35^{\circ} 31^{\prime} \mathrm{N}, 140^{\circ} 03^{\prime} \mathrm{E}\right)$ is an artificial channel constructed between a past coastline and land that was reclaimed in the 1960s, and is located near the mouth of the Yoro River, in the northeastern part of the bay. The Obitsu site (OB; 35 $\left.24^{\prime} \mathrm{N}, 139^{\circ} 54^{\prime} \mathrm{E}\right)$ is located on the Obitsu River estuary on the east coast of the bay. Wide areas of natural saltmarsh have been conserved in the delta of the Obitsu River. The Yokohama site (YK; $35^{\circ} 27^{\prime} \mathrm{N}, 139^{\circ} 37^{\prime}$ E) is located at the mouth of the Katabira River on the west coast of the bay, where artificial saltmarshes were created in the late 1990s (The Sea Beautification Society 2006). The TS and YK study sites are characterized by small mudflats (3.2 and 0.2 ha, respectively) containing small saltmarsh patches, while the $\mathrm{OB}$ and $\mathrm{SH}$ sites comprise wide tidal flats (approximately 1250 and 30 ha, respectively) with wide areas of saltmarsh.

To clarify the life history of $C$. sinense, field observations were carried out monthly from July, 2011, to March, 2013, at the SHC site (which has the highest population density). At the SHS, TS, OB, and YK sites field observations were made monthly from April 2012 to March 2013. Crab samples were collected by hand during a 1-hour period from an area of $100 \mathrm{~m}^{2}(2 \times 50 \mathrm{~m})$ during low tide. The SHC site was prepared by piling $10-40 \mathrm{~cm}$ diameter cobble stones on the mud substratum across the intertidal slope.

The maximum carapace width $(\mathrm{CW})$ of each crab was measured to the nearest $0.1 \mathrm{~mm}$ using a hand caliper. The crabs were sexed on the basis of their abdominal structure, and ovigerous females were recorded. The sex of juvenile crabs less than $6.0 \mathrm{~mm} \mathrm{CW}$ could not be determined. Close attention was paid to collection of juvenile crabs by carefully inspecting shore debris, etc. Following observations and measurements, the crabs were released at their original place of capture. Crabs were defined as adults if larger than the smallest ovigerous female ( $\geq 8 \mathrm{~mm} \mathrm{CW}$ ), as established during the reproductive period in June to September, when ovigerous females are present (see Results).

\section{Statistical analysis}

Wilcoxon's signed-rank test was used to compare the mean abundance of adult crabs, followed by pairwise multiple comparisons to determine specific differences in abundance among sites. Significance levels were determined by the sequential Bonferroni technique using an experiment-wise error rate $\alpha=0.05$ (Dunn-Sidák method; Sokal \& Rohlf 1995). The densities of juveniles during the breeding season (June-September) were compared among the five sites using the chi-square test. All statistical analyses were performed using R 2.15.2 (R Development Core 


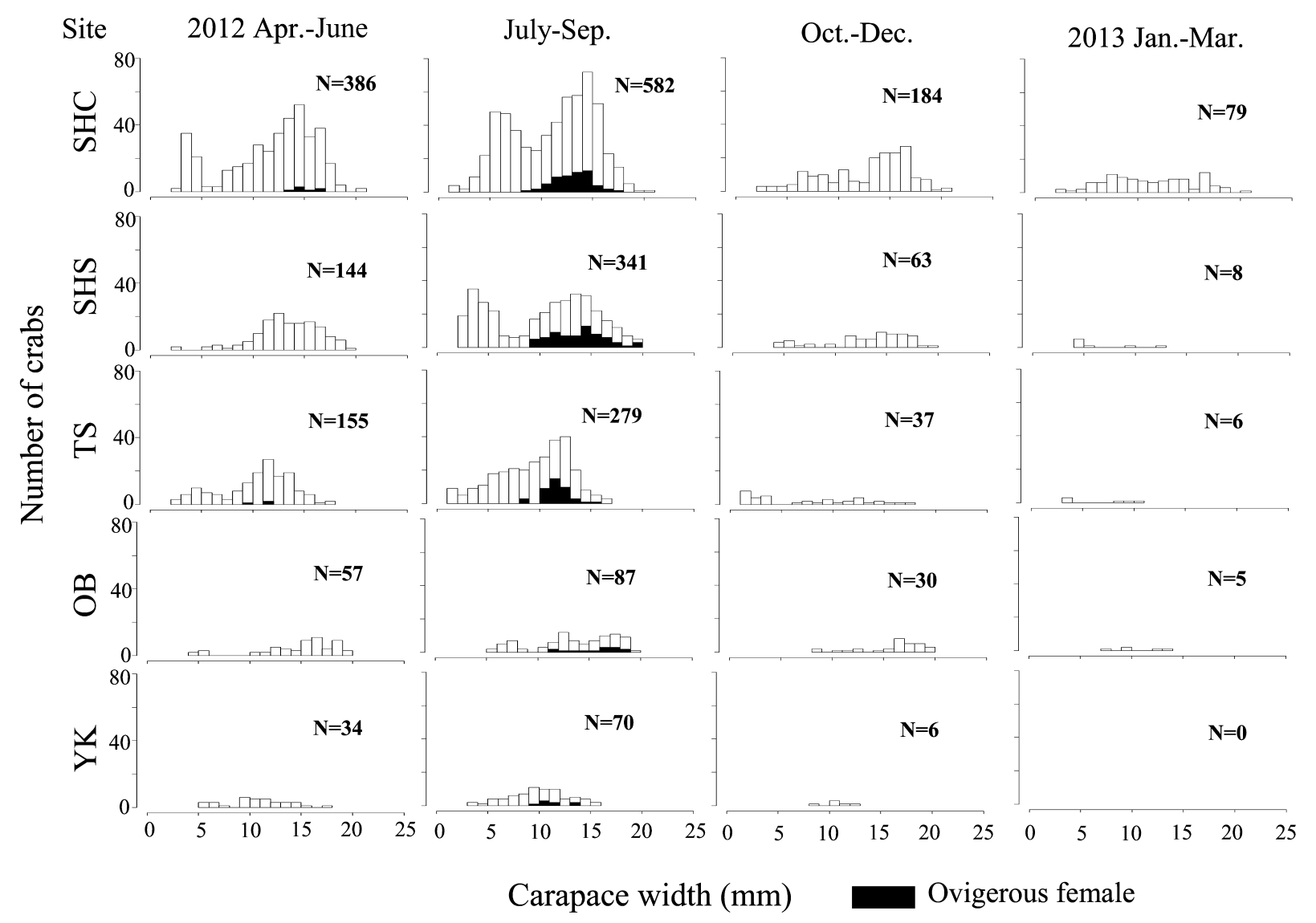

Fig. 2. Seasonal changes in the size-frequency distribution of Clistocoeloma sinense at five sampling sites in Tokyo Bay. Black bars indicate ovigerous females.

Team 2012). Seasonal size-frequency histograms were constructed for each observation time for each population, to clarify generation composition, growth of the cohort, breeding season, and recruitment of juvenile crabs (Pianka 1974). Modes in the size-frequency distributions of each sex were distinguished using the FiSAT II software package (FAO 2002). This was based on modal progression analysis of size-frequency data using Bhattacharya's method, which enabled estimations of change in mean $\mathrm{CW}$ for each cohort identified.

\section{Results}

Based on a total of 12 hours of field collection during the one-year study period (2012-2013), Clistocoeloma sinense was found to be most abundant at the SHC site ( $\mathrm{n}=1255$ : $\mathrm{cf}$. $\mathrm{n}=556,477,178$, and 110 at sites SHS, TS, OB, and YK, respectively). Seasonal changes in the size-frequency distribution of the crabs captured at each site during 2012 are summarized in Figure 2. At all sites the number of crabs increased from late spring (April-June) to late summer (July-September), coinciding with the occurrence of smaller crabs $(<6 \mathrm{~mm} \mathrm{CW})$ in the populations. During the colder period (October-March), the number of crabs tended to be low. Smaller crabs were more commonly found under small pieces of stranded wood and wet cloth during winter. There were significant differences $(p<0.001$; see below) in the mean number of adult crabs among the five sites during the reproductive season, when ovigerous females were present. A greater number of adult crabs was present in 2011 (mean \pm standard error: $92.3 \pm 18.0)$ than in 2012. The numbers of adult crabs at SHC (147.8 \pm 8.8$)$, SHS (79.5 \pm 10.6$)$, and TS $(65.0 \pm 5.7)$ were significantly higher than at the $\mathrm{OB}(23.0 \pm 4.1)$ and YK $(16.0 \pm 2.0)$ sites.

The breeding season, in terms of the occurrence of ovigerous females and the percentage of ovigerous females at each site, is shown in Figure 3. At all sites, ovigerous females were found in a single peak of occurrence during summer (July-August). The smallest ovigerous female ( $8.0 \mathrm{~mm} \mathrm{CW}$; the minimum size for reaching maturity) was found at the TS site. A total of 372 ovigerous females were collected during the study (mean CW $12.9 \mathrm{~mm}$; range $8.0-19.5 \mathrm{~mm}$ ).

In 2011, ovigerous females occurred in July at the SHC site, with the peak number in August comprising 69\% of the total adult females. Few ovigerous females were present in September 2011, and none were found after October. 



Fig. 3. Seasonal variation in the percentage of ovigerous adult females at five sampling sites in Tokyo Bay during the 3 years of the study.

In 2012, ovigerous females were first found in June, comprising $33 \%-37 \%$ of the adult females in each of July and August, and were absent in October. The seasonal pattern of occurrence of ovigerous females in 2012 was similar to that observed in 2011. At the other study sites, the percentage of ovigerous females was high during late July to August, with single peaks of occurrence comprising, at each site, $59 \%$ (SHC), $76 \%$ (TS), 79\% (OB), and $75 \%(\mathrm{YK})$ of the total adult females (Fig. 3).

Unsexed juvenile crabs (3-6 mm CW) were found at all sites from spring to autumn (Fig. 4). The number of juvenile crabs was highest at the SHC site, followed by the SHS, TS, OB and YK sites. The proportion of juveniles in the total crab population during the breeding season (June-September) was $0.28,0.27,0.32,0.14$, and 0.23 at
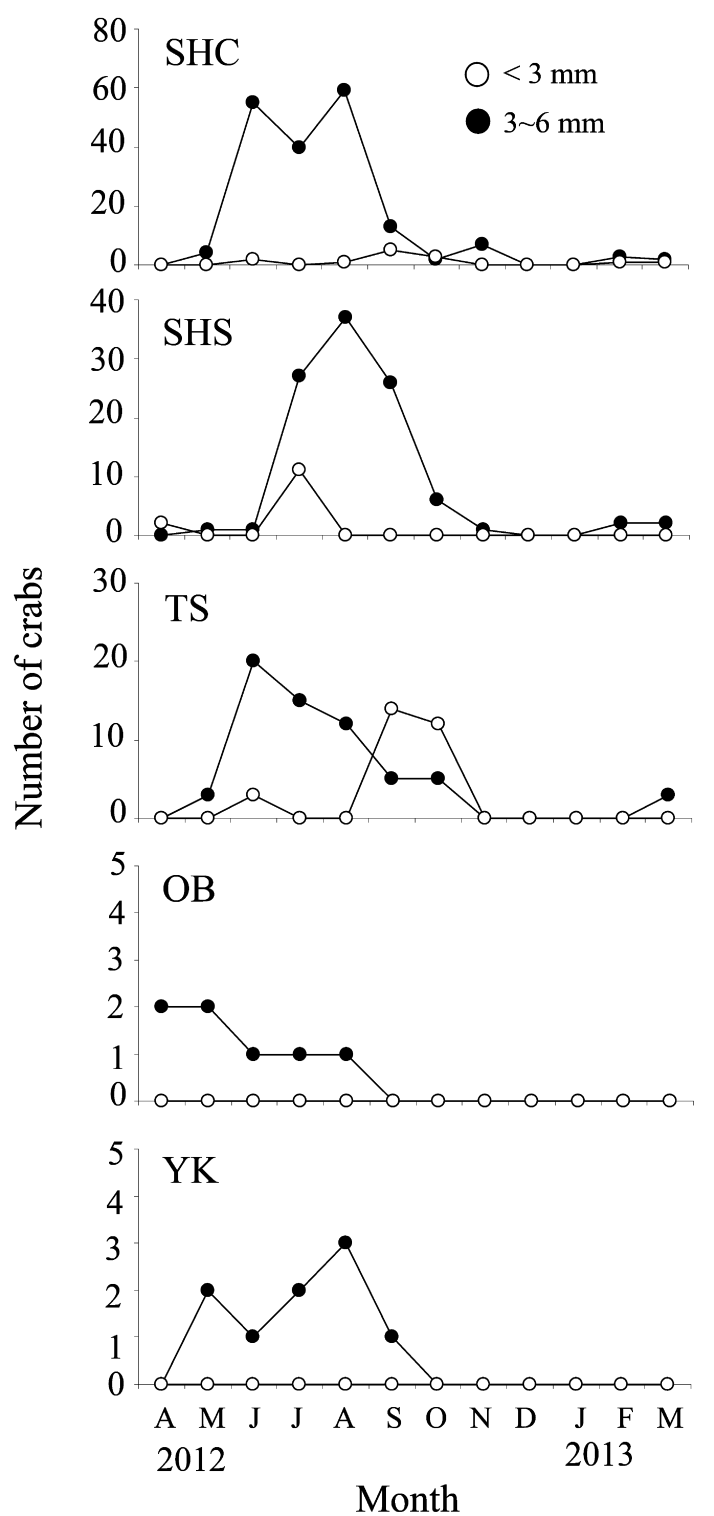

Fig. 4. Seasonal variations in the number of small (CW $<3 \mathrm{~mm}$ ) and large (CW 3-6 mm) juvenile crabs at five sampling sites in Tokyo Bay.

the SHC, SHS, TS, OB, and YK sites, respectively. Significant differences were found in the percentage of juveniles among sites $(p<0.01)$. The OB site had a lower percentage of juveniles $(p<0.01)$ than the other sites. The number of newly recruited juveniles $(<3 \mathrm{~mm} \mathrm{CW})$ is shown in Figure 4. A clear peak in the occurrence of new recruits was observed only at the TS site, which showed a maximum in autumn (September and October). The number of new recruits was low at the other sites, and none were observed at the OB and YK sites.

During the study period, the greatest number of crabs was observed at the SHC site (677 males, 958 females, 177 juveniles). Seasonal changes in the size distribution of crabs at the SHC site are shown in Figure 5, based on 
a

Males

Females

Males

Females

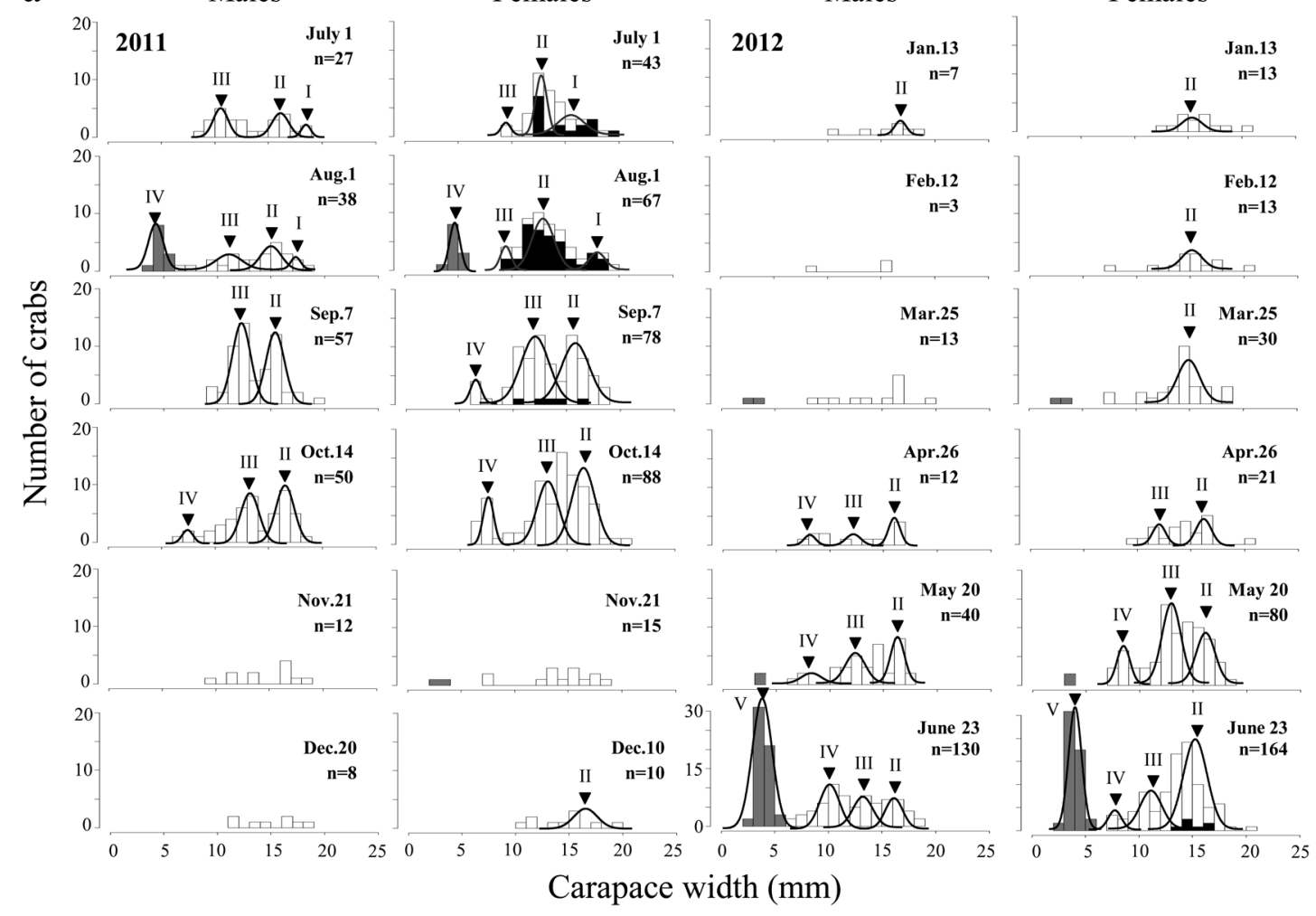

b

Males

Females

Males

Females



Fig. 5. Size-frequency distributions of Clistocoeloma sinense from July 2011 to March 2013 at the SHC site in Tokyo Bay. Unsexed juveniles were assigned genders assuming a sex ratio of 1:1. The roman numerals I-VI refer to the 2007-2012 cohorts, respectively. Black bars, ovigerous females; gray bars, unsexed juveniles. 
which six cohorts were identified among both males and females during the 21 months of the study. As each cohort (except for the smallest cohort which occurred in September but disappeared in winter) grew in one year to a size similar to the next largest cohort, the cohorts are presumed to represent annual recruiting.

The growth of each cohort was evident in the seasonal change in the mean $\mathrm{CW}$ (Fig. 6). There was no apparent difference in growth between males and females. The youngest cohort (Cohort VI), which was recruited in September 2012 with a mean $\mathrm{CW}$ of $2.9 \mathrm{~mm}$, grew to $3.7 \mathrm{~mm}$ by November 2012, prior to overwintering. However, this cohort disappeared during the winter. The second youngest cohort (Cohort V) was recruited in June 2012 with a mean $\mathrm{CW}$ of $3.6 \mathrm{~mm}$, although a small number of similar-sized juveniles had been collected in March 2012. These juveniles may have been recruited in the previous year, then overwintered. Cohort V grew rapidly to $\mathrm{CW} 6.0-7.0 \mathrm{~mm}$ by March 2013, following their presumptive second overwintering. The third youngest cohort (Cohort IV) appeared in August 2011 (mean CW $4.6 \mathrm{~mm}$ ). This cohort was probably recruited during autumn of the previous year. The females of Cohort IV grew to $\mathrm{CW} 8.7 \mathrm{~mm}$, and attained a mature size by July 2012, following their second overwintering. The third largest cohort (Cohort III) was found at the beginning of the study (July, 2011; mean CW 8.7$10.1 \mathrm{~mm}$ ), indicating that this cohort had reached maturity. They may have been recruited in 2009 and overwintered for 2 years (2 years old). This cohort grew to a CW of approximately $14 \mathrm{~mm}$ by July, 2012, and had reached $16 \mathrm{~mm}$ by March 2013 (4 years old). The second largest cohort (Cohort II) was also present at the beginning of the study (July 2011), with a mature CW of $12.1-15.5 \mathrm{~mm}$. They were probably recruited in 2008 and had overwintered three times ( 3 years old). This cohort grew slowly and had grown to a CW of $16.5-18.1 \mathrm{~mm}$ by July 2012 (4 years old). Cohort II disappeared following the summer breeding season in 2012, and had probably died. The largest cohort (Cohort I) of both sexes (CW 14.8-18.0 mm at the beginning of the study) was probably recruited in 2007 (four overwinterings; 4 years old); this cohort disappeared following the breeding season and had probably died. This analysis of seasonal changes in size suggests that the lifespan of sesarmid crabs is 4 years for both sexes. The occurrence of yearly cohorts and the co-occurrence of juveniles and ovigerous females in every year of the study clearly indicate that stable turnover of this crab population is occurring.

\section{Discussion}

Analysis of monthly changes in the size-frequency distribution and occurrence of ovigerous females of the endangered sesarmid crab Clistocoeloma sinense at the innermost site (Shinhama lagoon, SHC; Figs 5 and 6) in Tokyo Bay suggested that the lifespan for both males and females is approximately 4 years. The females commenced breeding in their second summer. The breeding season, indicated by the presence of ovigerous females at each of the five study sites, was estimated to be from June to September, with a peak from July to August, suggesting that the crab breeds once each year (Fig. 3). The longevity of other grapsid species inhabiting intertidal saltmarshes in west Pacific Ocean estuaries ranges from 2 to 4 years: 2-3 years for Parasesarma pictum in Hong Kong (Yau 1992); 3-4 years for Parasesarma affine in Hong Kong (reported as $P$. plicatum in Kowk 1995); 3-4 years for Perisesarma bidens in Hong Kong (Kwok 1995); and 3.0-3.8 years for Chiromantes dehaani and Helice tientsinensis in the Yangtze River Estuary, China (Chu et al. 2013). These data suggest that $C$. sinense has similar longevity to other saltmarsh grapsid crabs in northwest Pacific estuaries. In addition, females of the four grapsid crabs Helice tridens in Kumamoto, Kyushu, Japan (Baba 1978), P. pictum, P. affine and P. bidens in Hong Kong (Yau 1992; Kwok 1995) reach maturity during the first summer following settlement, whereas in this study in Tokyo Bay, C.sinense commenced breeding in the second summer following settlement. This comparison of life histories among saltmarsh crab species suggests that $C$. sinense in Tokyo Bay has similar longevity, but takes longer time to reach maturity.

As discussed above, the life cycle of $C$. sinense is characterized by slow growth. This crab is a habitat specialist living under partially buried stranded materials including wood, rock piles, clothes and plant litter at the edge of saltmarshes near the high tide mark (Hashiguchi \& Miyake 1967). The color and pattern of the carapace of the crab are very similar to the mud surface in their habitat (Hsueh \& Huang 1996). The crab adopts thanatosis behavior probably when it is detected by predators such as mammals and birds (Osaka Museum of Natural History 2008). It forages only at night (Koike \& Furota pers. obs.), feeding on reed litter and other plants (Kon et al. 2013) near its daytime location. This reclusive behavior may be an adaptation to predator avoidance, but nutritional intake may be low because of the low nitrogen content of the litter (Linton \& Greenaway 2000, Hartnoll 2006). This reclusive behavior of $C$. sinense is closely related to the habitat characteristics of the species which are unique in the study area. Thus, conservation and restoration of the uppermost zone of estuarine intertidal marshes that are severely affected by human activities may be a strategy fundamental to maintaining local populations of $C$. sinense.

Recruits $(<6 \mathrm{~mm} \mathrm{CW})$ and breeding females were found at every site in each year of the study, even at the small newly constructed artificial habitat site (YK). Yuhara et al. (2014) reported the absence of genetic heterogeneity in mtDNA among all crab populations along the coast of Tokyo Bay, suggesting connectivity among local populations in the bay through larval dispersal. The crab has a planktonic life stage of approximately 10 days (Saba 1972; Yuhara pers. obs.), which may be sufficient to enable trans- 




b

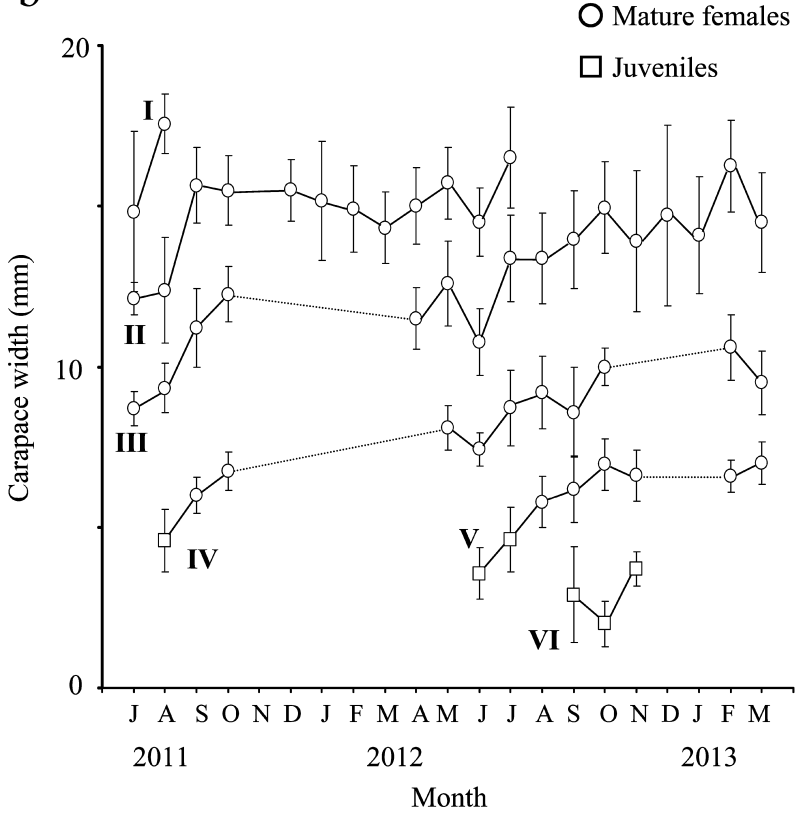

Fig. 6. Estimates of the growth rate of cohorts of Clistocoeloma sinense, based on data in Fig. 5. (a) Data for males. Vertical bars, 1 standard deviation. (b) Data for females.

port to other local habitats in the bay. Bay water may provide a larval pool as a stock of new generations for each local crab population in the bay; thus, each local crab population along the bay may be a constituent of the Tokyo Bay metapopulation.

Populations of $C$. sinense in the bay were found mainly in small saltmarsh habitats that occurred in artificial channels (Yuhara et al. 2013). At a natural marsh site (OB), which is the largest saltmarsh in Tokyo Bay, the crab den- sity was relatively low, suggesting that crab density does not depend on habitat scale. Small but stable mud flats with reed vegetation along the coast of the bay may be the most important habitats for conservation of the Tokyo Bay regional metapopulation of this crab.

\section{Acknowledgements}

We are grateful to Drs K. Okoshi, M. Kagami, and M. Taru (Toho University) for valuable advice and suggestions. We also thank Y. Koike, A. Abe, K. Moutai, T. Fukuda, K. Kato, and Y. Tatara (Toho University) for assistance in the field. We are also grateful to the editor and two anonymous referees for constructive comments on the manuscript. Special thanks go to the Gyotoku Wildlife Sanctuary (Shinhama Lagoon) for granting permits to conduct this study.

\section{References}

Baba K (1978) Life story and general ecology of sesarmin crabs. Benthos Res 15/16: 23-27.

Chu TJ, Sheng Q, Wang SK, Huang MY, Wu JH (2013) Population dynamics and secondary production of crabs in a Chinese salt marsh. Crustaceana 86: 278-300.

Dai AY, Yang SL (1991) Crabs of the China Seas. Ocean Press, Beijing, $681 \mathrm{pp}$.

FAO (2002) FISAT-II, Software Version 1.1.2. FAO-ICLARM Stock Assessment Tools, Rome. Available at: http://www.fao. org/fishery/topic/16072/en (accessed on 19 Feb 2014)

Furota T (2000) Naiwan no kairui, zetsumestu to hozen: Tokyo wan no umininarui suitai karano kousatsu [Extinction and conservation of mollusks in enclosed waters, a consideration from population decline in the batillariid snails in Tokyo Bay]. Kaiyo Monthly (supplement) 20: 74-82. (in Japanese)

Furota T (2007) Tokyo Wan [Tokyo Bay]. In: Dai 7 kai Shizen Kankyo Hozen Kiso Chosa Senkai-iki Seitaikei Chosa (Higata Chosa) Houkokusho [The 7th National Survey on the Natural Environment: Shallow Sea Survey (Tidal Flats)] (ed Iijima A). Biodiversity Center, Nature Conservation Bureau, Ministry of the Environment, Yamanashi, pp. 39-47. (in Japanese)

Hashiguchi Y, Miyake Y (1967) Ecological studies of marsh crabs, Sesarma spp. I-Hibernation, crab's habitat and parasitic animals in winter. Science bulletin of the Faculty of Agriculture, Kyushu University 23: 67-80. (in Japanese)

Hartnoll RG (2006) Reproductive investment in Brachyura. Hydrobiologia 557: 31-40.

Hsueh PW, Huang JF (1996) A new record of Clistocoeloma sinense Shen, 1933, from Taiwan (Decapoda, Brachyura, Grapsidae, Sesarminae), with notes on its distribution and ecology. Crustaceana 69: 63-70.

Japanese Association of Benthology (2012) Threatened Animal of Japanese Tidal Flats: Red Data Book of Seashore Benthos. Tokai University Press, Kanagawa, 285 pp. (in Japanese)

Kamita T (1941) Studies of the Decapod Crustaceans of Chosen. The Fisheries Society of Chosen, Keijo, 281 pp. (in Japanese) Kon K, Hoshino Y, Kanou K, Okazaki D, Nakayama S, Kohno H 
(2013) Benthic food web of a salt marsh in an artificial lagoon, central Japan. Aquat Ecosyst Health Manag 16: 40-50.

Kwok PW (1995) The ecology of two sesarmaine crabs, Perisesarma bidens (de Haan) and Parasesarma plicata (Latreille) at the Mai Po Marshes Nature Reserve. Hong Kong. PhD thesis. The University of Hong Kong, Hong Kong.

Linton SM, Greenaway P (2000) The nitrogen requirements and dietary nitrogen utilization for the gecarcinid land crab Gecarcoidea natalis. Physiol Biochem Zool 73: 209-218.

Lotze HK, Lenihan HS, Bourque BJ, Bradbury RH, Cooke RG, Kay MC, Kidwell SM, Kirby MX, Peterson CH, Jackson JBC (2006) Depletion, degradation, and recovery potential of estuaries and coastal seas. Science 312: 1806-1809.

Osaka Museum of Natural History, Osaka Natural History Center (eds) (2008) Higata wo kangaeru, Higata wo asobu [Tidal flat: understanding and enjoying the nature]. Tokai University Press, Kanagawa, 159 pp. (in Japanese)

Pianka PR (1974) Evolutional Ecology. Harper \& Row, New York, $356 \mathrm{pp}$.

R Development Core Team (2012) R: a language and environment for statistical computing [Internet]. Vienna (Austria): R Foundation for Statistical Computing. Available at: http:// www.R-project.org (accessed on 19 Feb 2014)

Saba M (1972) Umore-benkeigani no koukihassei [Studies on the post-embryonic development of Clisotocoeloma merguiense de Man]. Mie-seibutsu 22: 25-29. (in Japanese)

Sakai T (1976) Crabs of Japan and the Adjacent Seas, Kodansha,
Tokyo. 773 pp. (in Japanese)

Sato M (2010) Anthropogenic decline of the peculiar fauna of estuarine mudflats in Japan. Plankton Benthos Res 5 (Supplement): 202-213.

Sokal RR, Rohlf FJ (1995) Biometry: The principles and practice of statistics biostatistical analysis. 3rd edition. W.H. Freeman, New York, 887 pp.

The Committee of the Red Data Book Chiba (2011) The important species for protection in Chiba Prefecture, Red Data Book Chiba 2011-Animals. Nature Conservation Division, Enviromental and Community Affairs Department, Chiba Prefectural Government, Chiba, 431 pp. (in Japanese)

The Sea Beautification Society (2006) Hama no umi zukuri [Productive Sea of Yokohama]. Seizando, Tokyo, 215 pp. (in Japanese)

Yau PM (1992) The population dynamics of Parasesarma picta (Decapoda Grapsidae) and Thalamita danae (Decapoda: Portunidae) in Hong Kong. Asian Mar Biol 9: 167-180.

Yuhara T, Taru M, Furota T (2013) Distribution of macrobenthos species in Tokyo Bay and the importance of artificial channels for the conservation of endangered macrobenthos species. Jpn J Benthol 68: 16-27. (in Japanese with English abstract)

Yuhara T, Kawane M, Furota T (2014) Genetic population structure of local populations of the endangered saltmarsh sesarmid crab Clistocoeloma sinense in Japan. PLoS ONE 9(1): e84720. doi: 10.1371/journal.pone.0084720. 